\title{
Early Treatment of a Progressive Rasmussen's Like Syndrome with Ganciclovir
}

\author{
Richard S. McLachlan, David Diosy, Simon Levin
}

\begin{abstract}
Background: Escalating focal sensorimotor seizures, progressive neurologic deficit and cognitive decline with associated typical magnetic resonance imaging (MRI) findings or pathological confirmation constitute the syndrome of Rasmussen's encephalitis. Methods: Three patients with this clinical scenario had long-term follow-up after being given the antiviral drug ganciclovir $10 \mathrm{mg} / \mathrm{kg} / \mathrm{day}$ IV for ten days within one to three months of disease onset. Results: Seizures occurred at least hourly and were localized to the Rolandic region. The MRIs were normal in one patient and in two showed changes consistent with ongoing seizures. Two patients, one whose short-term outcome was reported previously, had immediate and sustained cessation of seizures and resolution of their neurologic deficit. One patient with seizures from both hemispheres did not respond and went on to hemispherectomy that confirmed chronic encephalitis. Seizures continued in five other patients treated 6 to 72 months after disease onset. Conclusion: The sustained seizure control after ganciclovir in two of three patients suggests this drug may be effective when given early in the course of this subacute intractable focal epilepsy syndrome.
\end{abstract}

\begin{abstract}
RÉSUMÉ: Traitement précoce par le ganciclovir du syndrome évolutif ressemblant à la maladie de Rasmussen. Contexte : L'encéphalite du syndrome de Rasmussen comprend des crises convulsives sensitivomotrices focales croissantes, un déficit neurologique progressif et un déclin cognitif avec des constatations typiques à l'IRM ou à la confirmation anatomopathologique. Méthode : Trois patients qui présentaient ce tableau clinique ont été suivis à long terme après un traitement par le ganciclovir IV à $10 \mathrm{mg} / \mathrm{kg} / \mathrm{jr}$ pendant 10 jours, instauré de 1 à 3 mois après le début de la maladie. Résultats : Les patients présentaient des crises convulsives au moins à toutes les heures et elles étaient localisées à la région de Rolando. L'IRM était normal chez un patient et présentait des changements compatibles avec des crises convulsives en cours chez les deux autres. Deux patients, incluant un dont l'issue à court terme a déjà été rapportée antérieurement, ont présenté un arrêt immédiat et prolongé des crises convulsives et une résolution du déficit neurologique. Un patient qui présentait des crises convulsives provenant des deux hémisphères n'a pas répondu au traitement et il a subi ultérieurement une hémisphérectomie qui a confirmé le diagnostic d'encéphalite chronique. Les crises convulsives ont persisté chez 5 autres patients traités entre 6 et 72 mois après le début de la maladie. Conclusion : Le contrôle prolongé des crises convulsives après traitement par le ganciclovir chez deux de ces trois patients suggère que ce médicament peut être efficace quand il est administré tôt au cours de l'évolution de ce syndrome épileptique focal subaigu, résistant au traitement.
\end{abstract}

Can J Neurol Sci. 2011; 38: 296-298

According to the European consensus statement, escalating focal sensorimotor seizures, progressive neurologic deficit and cognitive decline, usually in childhood, characterize Rasmussen's syndrome when associated with typical magnetic resonance imaging (MRI) or pathology findings. ${ }^{1,2}$ The disease is defined pathologically by a microglial nodular chronic encephalitis that is usually regionally accentuated in the Rolandic cortex but can predominate in other areas. Although no cause has been identified, both immune mediated and infectious etiologies have been suggested. Various treatments aimed at modulation of the immune system such as intravenour immunoglobulin (IVIG) or plasmapheresis have been of transient or no benefit. The only treatment that reliably stops progression is hemispherectomy. We used early treatment with ganciclovir, an antiviral drug used primarily for cytomegalovirus (CMV) infection, in three patients with a Rasmussen's like syndrome (they lacked the typical MRI findings or pathological confirmation required by the European concensus to diagnose

\footnotetext{
From the Department of Clinical Neurological Sciences, University of Western Ontario, London, Canada.

Received August 25, 2010. Final Revisions Submitted October 20, 2010. Correspondence to: Richard S. McLachlan, London Health Sciences Centre-University Hospital, London, Ontario, N6A 5A5, Canada.
} 


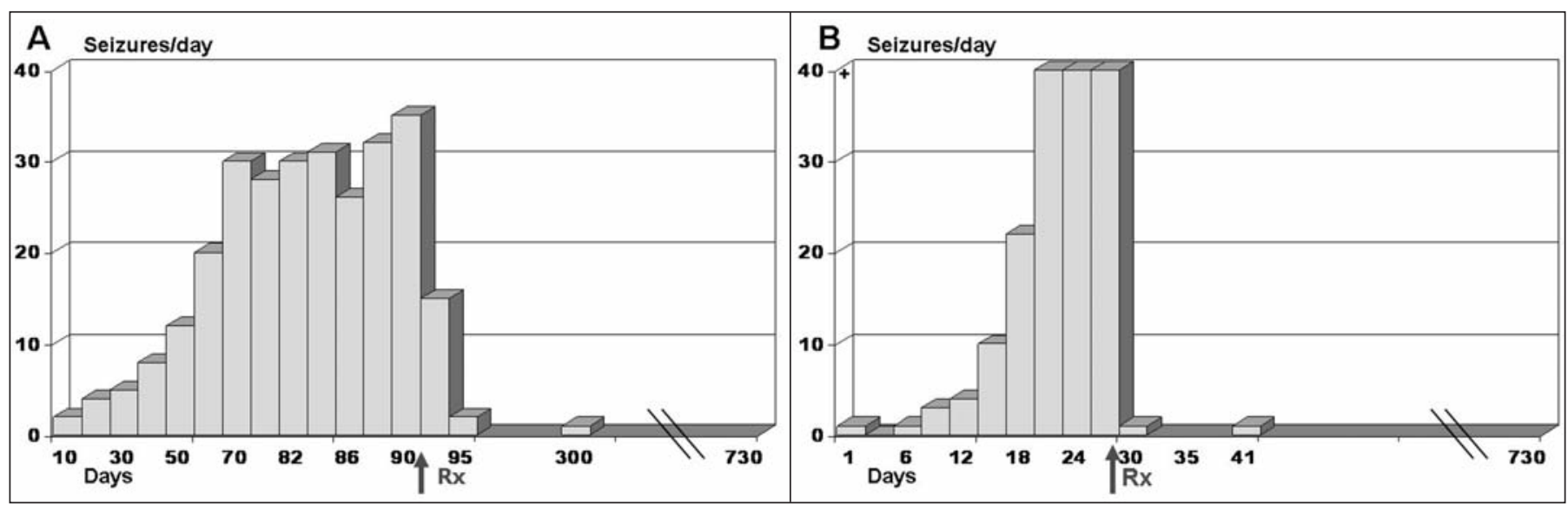

Figure: Number of seizures per day before and after treatment with ganciclovir (Rx= time of treatment). A) Patient 1 B) Patient 2.

Rasmussen's encephalitis). METHODS

Three patients age 5, 7 and 20 years with progressive focal motor seizures, increasing neurologic deficit and cognitive impairment were admitted for consideration of surgical management of intractable seizures. A trial of the antiviral drug ganciclovir $10 \mathrm{mg} / \mathrm{kg} /$ day IV was given for ten days prior to proceeding to surgery. Treatment was started within one to three months of the onset of the first seizure in all three. Five other patients with pathologically confirmed Rasmussen's encephalitis were treated 6-72 months after seizure onset.

\section{Results}

Electroencephalography (EEG) showed interictal and ictal abnormalities centered in the Rolandic region. In two patients the MRI showed focal changes in the Rolandic area that were thought to relate to ongoing seizure activity and in the other it was normal. Two of the three patients had rapid cessation of frequent daily seizures during treatment and returned to normal. There was no response to two trials of ganciclovir in the other patient who went on to hemispherectomy and pathological confirmation of chronic encephalitis. No long-term impact on seizures or neurologic deficits was found in the five patients treated six months or more after disease onset. There were no adverse effects from ganciclovir.

\section{Patient 1}

A previously reported seven-year-old girl had sudden onset of seizures consisting of tingling then jerking of the left arm progressing to the left face and leg for 10-30 seconds. ${ }^{3}$ These escalated over a month from 2 to 30/day with frequent secondary generalization despite triple antiseizure drug therapy. At the same time, she developed progressive mild left hemiparesis, behaviour change and cognitive difficulties without fever or systemic symptoms. Three weeks before the first seizure she had a mild case of chicken pox that resolved completely. The EEG revealed right hemisphere background slowing and frequent multifocal right hemisphere spikes maximum over the Rolandic region. Seizures originating from the right post-central gyrus were recorded using implanted subdural electrodes. Magnetic resonance imaging was normal. Cerebral spinal fluid (CSF) cells and protein were normal. Serum antibodies were positive for CMV, mycoplasma and Varicella zoster but these were not seen in CSF. Prior to planned resective surgery, she was given a ten day trial of IV ganciclovir. After five days, seizures stopped (Figure $\mathrm{A}$ and $\mathrm{B}$ ), her hemiparesis and cognitive deficit disappeared and her EEG became normal. Short-term outcome was reported previously as seizure free but after two years, rare focal motor seizures of the left hand recurred when antiseizure medication was discontinued. Seizures were controlled after drug monotherapy was re-established. Now at age 21 years she is neurologically intact, attends college and is still on an antiseizure drug.

\section{Patient 2}

A previously well 20-year-old woman had sudden onset of focal seizures starting as pain and twitching in the right hand progressing to the shoulder and face, rightward head deviation, inability to speak often followed by a generalized convulsion. Over one month, these progressed from two seizures per week to four per hour despite polytherapy with three antiseizure drugs. She developed right hemiparesis with inability to walk, mild aphasia and impaired cognition. The EEGs revealed background slowing, persistent spikes and recurrent seizures in the left rolandic region. Magnetic resonance imaging showed increased T2 signal in the left rolandic cortex. Cerebral spinal fluid was normal and viral antibody titres were negative. Prior to scheduled epilepsy surgery and during a ten day course of IV ganciclovir, seizures stopped (Figure B). Her neurologic deficits resolved over the following three weeks. After three years she is neurologically normal and seizure free off medication. The EEG and MRI were normal.

\section{Patient 3}

A healthy five-year-old girl developed focal motor seizures starting in the right hand continuing as a Jacksonian march to 
right hemiclonic then a secondarily generalized seizure occurring five times/week. Convulsions were controlled with medication but she progressed over one month to epilepsia partialis continua of the right hand. There was associated language regression and right hemiparesis. The EEG showed diffuse background slowing, multifocal spikes from both hemispheres maximum left and left hemisphere seizures. Magnetic resonance imaging revealed increased signal and "sulcul crowding" in the left Rolandic cortex. Cerebral spinal fluid was normal. Ganciclovir IV for ten days was given two months after seizure onset and again at three months but seizures continued unchanged. A course of IVIG at three months resulted in decreased seizures to one to two/week. She began to speak and use her right hand but after seven months seizures were again daily with loss of hand function and no expressive language. Independent seizures appeared from the right hemisphere. Epilepsia partialis continua returned and 15 months after seizure onset she underwent a left functional hemispherectomy. Pathology was widespread and typical for Rasmussen's encephalitis. Seizures decreased to two/week. Now at age 16 years she has right hemiplegia, says only two or three words and continues to have secondarily generalized seizures from the right hemisphere at least once a week.

\section{Discussion}

None of the three patients fulfilled the European consensus diagnostic criteria for Rasmussen's encephalitis ${ }^{2}$ at the time of treatment with ganciclovir since they did not have the typical MRI abnormalities or pathological confirmation of the disease. However, the clinical course of their disease was consistent with early Rasmussen's syndrome and no other cause was found. Since MRIs were done two to three months into the illness, the expected changes may not yet have developed early in the disease as has been reported by others. ${ }^{4}$ The symptoms, signs and progression were similar in all three subjects except for evidence of more severe bihemispheric disease in Patient 3 who went on later to surgery and pathologic confirmation of the diagnosis.

Post-infectious, acute disseminated and Rasmussen's encephalitis are in the differential diagnosis in these patients but sudden spontaneous resolution of any of these conditions would be unusual. Since it is unlikely that seizures stopped by chance during treatment in our two patients, the dramatic sustained improvement observed while receiving ganciclovir supports a viral etiology for the condition. We have seen only one other patient with a similar history consistent with Rasmussen's syndrome who had sustained seizure control without surgery (during treatment with tacrolimus) and the recovery took months not days.

\section{Conclusions}

There is suggestive evidence of an autoimmune disorder in Rasmussen's encephalitis ${ }^{5}$ but immunomodulatory therapy has been of limited benefit., 6 Based on the prevalence of cytomegalovirus genome in the brains of these patients ${ }^{8}$, we began using ganciclovir, an inhibitor of viral replication as treatment. We have treated a total of eight patients but the three in this report are the only ones treated within three months of onset of the illness. No meaningful improvement occurred in the five patients with pathologically confirmed Rasmussen's encephalitis treated well after three months of onset. ${ }^{3}$ Although our patients did not meet the clinical criteria from the European consensus for diagnosis of Rasmussen's at the time of treatment, we argue this is the same condition but at an early less advanced stage. This view is supported by the one patient who went on to pathologic confirmation of the disease. That this treatment appears to be effective only when given early in the course of the illness raises the possibility that the pathogenesis may initially be viral over the first few weeks or months, only later changing to an autoimmune basis. Early recognition and treatment of this progressive syndrome, whatever one elects to call it, is important if ganciclovir therapy is to be of any benefit. Further, if Rasmussen's encephalitis according to the European criteria is diagnosed, then a ten day course of ganciclovir within three months of onset may be beneficial.

\section{REFERENCES}

1. Rasmussen T, Olszewski J, Lloyd-Smith D. Focal seizures due to chronic localized encephalitis. Neurology. 1958; 8: 435-45.

2. Bien CG, Granata T, Antozzi C, et al. Pathogenesis, diagnosis and treatment of Rasmussen encephalitis: a European consensus statement. Brain. 2005; 128: 454-71.

3. McLachlan RS, Levin S, Blume WT. Treatment of Rasmussen's syndrome with ganciclovir. Neurology. 1996; 47: 925-8.

4. Lee JS, Juhász C, Kaddurah AK, Chugani HT. Patterns of cerebral glucose metabolism in early and late stages of Rasmussen's syndrome. J Child Neurol. 2001; 16: 798-805.

5. Freeman JM. Rasmussen's syndrome: progressive autoimmune multifocal encephalopathy. Pediatr Neurol. 2005; 32: 295-9.

6. Granata T, Fusco L, Gobbi G, et al. Experience with immunomodulatory treatment in Rasmussen's encephalitis. Neurology. 2003; 61: 1807-10.

7. Bien CG, Gleissner U, Sassen R, Widman G, Urbach H, Elger CE. An open study of tacrolimus therapy in Rasmussen encephalitis. Neurology. 2004; 62: 2106-9.

8. Power C, Poland SD, Blume WT, Girvin JP, Rice GPA. Cytomegalovirus and Rasmussen's syndrome. Lancet. 1990; 336: 1282-4. 